\title{
Spatial distribution and seasonal variation of four current-use pesticides (CUPs) in air and surface water of the Bohai Sea, China
}

\author{
Lin Liu ${ }^{\mathrm{a}, \mathrm{c}}$, Jianhui Tang ${ }^{\mathrm{a}, *}$, Guangcai Zhong ${ }^{\mathrm{b}}$, Xiaomei Zhen ${ }^{\mathrm{a}, \mathrm{b}, \mathrm{c}}$, Xiaohui Pan ${ }^{\mathrm{a}}$, Chongguo Tian ${ }^{\mathrm{a}}$ \\ a Key Laboratory of Coastal Environmental Processes and Ecological Remediation, Yantai Institute of Coastal Zone Research, Chinese Academy of Sciences, Yantai 264003, China \\ b State Key Laboratory of Organic Geochemistry, Guangzhou Institute of Geochemistry, Chinese Academy of Sciences, Guangzhou 510640, China \\ c University of Chinese Academy of Sciences, Beijing 100049, China
}

\section{H I G H L I G H T S}

- Four CUPs were analyzed in air and surface water samples of the Bohai Sea.

- CUPs were presented dominantly in gas phase of atmosphere and in dissolved phase of seawater.

- High seawater CUP levels in August were found around the Yellow River Estuary.

- Volatilization from the surface water was an important source of trifluralin and chlorpyrifos to the air.

- Atmospheric deposition was an important input pathway of chlorothalonil into the Bohai Sea.

\section{A R T I C L E I N F O}

\section{Article history:}

Received 25 October 2017

Received in revised form 23 November 2017

Accepted 24 November 2017

Available online $\mathrm{xxxx}$

Editor: Jay Gan

\section{Keywords:}

Current-use pesticides (CUPs)

Chlorpyrifos

Chlorothalonil

Dicofol

Bohai Sea

Air-sea exchange

\section{G R A P H I C A L A B S T R A C T}

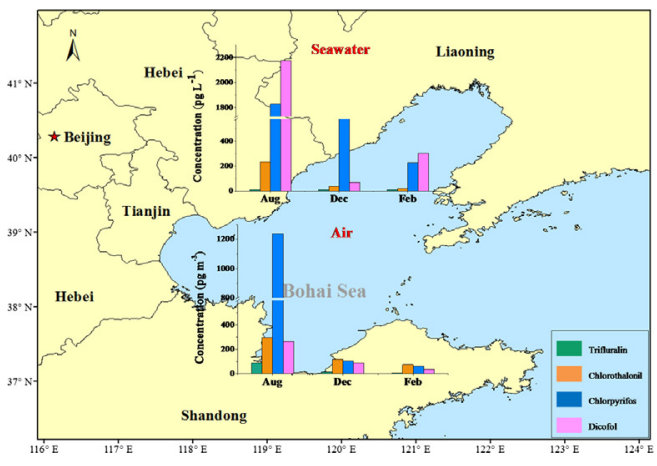

\section{A B S T R A C T}

Current-use pesticides (CUPs) are widely used in agriculture, and some are listed as persistent organic pollutants (POPs) due to their bioaccumulative and toxic properties. China is one of the largest producers and users of pesticides in the world. However, very limited data are available about the environmental fates of CUPs. Four CUPs (trifluralin, chlorothalonil, chlorpyrifos, and dicofol) in surface seawater and low atmospheric samples taken during research cruises on the Bohai Sea in August and December 2016 and February 2017 were analyzed, we added the spring data sampled in May 2012 to the discussion of seasonal variation. In our study, chlorpyrifos was the most abundant CUPs in the gas phase with a mean abundance of $59.06 \pm 126.94 \mathrm{pg} \mathrm{m}^{-3}$, and dicofol had the highest concentration dissolved in seawater (mean: $115.94 \pm 123.16 \mathrm{pg} \mathrm{L}^{-1}$ ). The concentrations of all target compounds were higher during May and August due to intensive use and relatively high temperatures in the spring and summer. Backward trajectories indicated that air masses passing through the eastern coast of the Bohai Sea contained high concentrations of pollutants, while the air masses from the Bohai and Yellow Seas were less polluted. The high concentration of pollutants in seawater was not only influenced by high yields from the source region of production or usage, but also by input from polluted rivers. Volatilization from surface water was found to be an important source of trifluralin and chlorpyrifos in the air. Air-sea gas exchange of chlorothalonil underwent strong net deposition (mean FRs: 51.67), which was driven by higher concentrations in air and indicates that the Bohai Sea acted as a sink for chlorothalonil.

(c) 2017 Elsevier B.V. All rights reserved.

\footnotetext{
* Corresponding author.

E-mail address: jhtang@yic.ac.cn (J. Tang).
} 


\section{Introduction}

Current-use pesticides (CUPs), are designed to be lower environmental persistence and toxic and be more biodegradable in comparison with traditional organochlorine pesticides (Walker and Nidiry, 2002). They are now among the catalog of 'emerging pollutants' (Mai et al., 2013). CUPs are not only identified in the regions where they are applied, such as agricultural and forestry areas (Arinaitwe et al., 2016; Asman et al., 2005; Feng et al., 2016; Yao et al., 2008a), rural and urban areas (Carratala et al., 2017; Coscolla et al., 2017; Estellano et al., 2015), but also in regions far away from their sources, such as the Arctic (Hoferkamp et al., 2010; Morris et al., 2016; Walker and Nidiry, 2002; Zhong et al., 2012a), high mountains (Hageman et al., 2006), the and Indian-Pacific Ocean (Bigot et al., 2016). China produces and consumes the largest amount of CUPs in the world. An estimated 3.74 million tons of technical pesticide products were produced in 2015, and 1.80 million tons were consumed in 2014 (www.stats.gov.cn). However, few data are available about the distribution and fates of CUPs in the marine environment (Zhong et al., 2014).

Seasonal variations of most types of CUPs in the atmosphere are related to their usage, with the highest concentrations measured in the spring or summer (Carratala et al., 2017; Estellano et al., 2015; Yao et al., 2008a; Zhong et al., 2012b). However, little is known about their seasonal distribution in the marine environment, especially in the highly human impacted Bohai Sea. Previous studies have revealed that seawater acts as a major recipient of numerous pesticides through dry or wet atmospheric deposition, riverine discharge, and air-water exchange (Feng et al., 2011; Luek et al., 2017; Mai et al., 2016; Zhong et al., 2011). Riverine inputs could be important sources not only for CUPs with relatively high water solubility, but also for CUPs with low water solubility (Zhong et al., 2014). CUPs can be transported by currents into the offshore and deep ocean regions, and hence threaten coastal and pelagic ecosystems (Carratala et al., 2017; Li et al., 2015; Mai et al., 2013). Airwater exchange is also an important process that transports CUPs. Seawater can act as a secondary source of pesticides, and release pesticides from the sea into the atmosphere. CUPs can then be delivered to remote regions by long-range air transport (LRAT).

The Bohai Sea is a semi-closed interior sea in China with a mean depth of $18 \mathrm{~m}$ and area of $70,000 \mathrm{~km}^{2}$ (Liu et al., 2012), and its water exchange with the Yellow Sea is relatively slow. Hence, pollutants tend to accumulate and become concentrated in this shallow water for a long time (Hu et al., 2010). The Bohai Sea is surrounded by the Liaoning, Hebei, and Shandong Provinces, and the Tianjin Municipality. The Bohai Economic Rim (BER) is one of the largest economic engines as well as the Yangtze and Pearl River Deltas in China. Besides the large population and rapidly growing industries, agriculture also plays a very important role in the BER. A large amount of pesticides is produced and applied in this region. For example, 300,900 tons of pesticides were used in the BER in 2015. Shandong province uses the largest amount of pesticides in China, and a total of 151,000 tons were applied for agricultural activities in 2015 (www.stats.gov.cn). The extensive use of pesticides has caused a series of environmental problems, and has seriously threatened human and ecosystem health.

Spatial distribution and seasonal trends of most pesticides were observed in previous studies in air (Coscollà et al., 2014; Scheyer et al., 2007; Yao et al., 2008b; Yao et al., 2006) and seawater (Bigot et al., 2016; Mai et al., 2013). The same area was studied in May 2012 for trifluralin, chlorothalonil, chlorpyrifos, dicofol and 10 additional contaminants (Zhong et al., 2014). Our work further deepened the previous research and were filled the gap about seasonal variations in the Bohai Sea. In this study, the concentrations of CUPs were measured during the summer (August 2016) and winter (December 2016 and February 2017), and previous study in spring (May 2012) was also added to our discussion of seasonal variations. Air-sea exchange of CUPs was estimated. The aim of this study was to understand the spatial and seasonal patterns of CUPs (trifluralin, chlorothalonil, chlorpyrifos, and dicofol) and identify potential sources in the Bohai Sea.

\section{Materials and methods}

\subsection{Sample collection}

Twenty-two air $\left(\sim 300 \mathrm{~m}^{3}\right)$ and seawater samples $(\sim 60 \mathrm{~L})$ were collected onboard a research vessel (Chuangxin I) from the Bohai Sea during three sampling campaigns (nine pairs of air and seawater samples in August-September 2016; nine pairs of air and seawater samples in December 2016,and four pairs of air and seawater samples in February 2017). Maps of the tracks for each air and seawater sample are shown in Fig. $S 1$ ( $A, B, C)$.

Individual air samples were collected in front of the upper-most deck of the research vessel by a high-volume air sampler for $\sim 24 \mathrm{~h}$ at a flow of $\sim 0.21 \mathrm{~m}^{3} \mathrm{~min}^{-1}$. Glass microfiber filters (Whatman ${ }^{\mathrm{TM}}, \mathrm{GF} / \mathrm{F}$, diameter $150 \mathrm{~mm}$ ) were used to collect particulate samples, followed by a glass column packed with PUF/Amberlite ${ }^{\mathrm{TM}} \mathrm{XAD}-2$ for gaseous samples in series (Zhong et al., 2014). Seawater samples were collected from the ship's seawater intake system, which was made of stainless steel and was located in the front of the vessel and $1 \mathrm{~m}$ below the waterline. The same glass microfiber filters (Whatman ${ }^{\mathrm{TM}}, \mathrm{GF} / \mathrm{F}$, diameter $150 \mathrm{~mm}$ ) were used to collect the particulate samples, and a selfpacked XAD-2 glass column $(30 \mathrm{~cm} \times 2.5 \mathrm{~cm}$ i.d., $30 \mathrm{~g}$ resin $)$ for the dissolved phase samples. After sampling, the glass columns were stored at $4{ }^{\circ} \mathrm{C}$, and filter samples were stored at $-20^{\circ} \mathrm{C}$. The details of air and water sampling information are given in Tables S1 and S2.

\subsection{Chemicals}

The analytical standards included four CUPs (trifluralin, chlorothalonil, chlorpyrifos, and dicofol). Individual trifluralin and chlorpyrifos standards were purchased from AccuStandard, America. Trifluralin-d14 (surrogate), and a pesticide-mix 323 containing chlorothalonil and dicofol were purchased from Dr. Ehrenstorfer, Germany. PCB-208, used for internal standards, was also purchased from AccuStandard, America.

\subsection{Extraction, cleanup, and analysis}

Samples were extracted using a modified Soxhlet extractor with dichloromethane (DCM) for $24 \mathrm{~h}$ (Xie et al., 2011). Prior to extraction, $10 \mathrm{ng}$ Trifluralin-d14 was added as a surrogate standard. The extracts were evaporated to $1 \mathrm{~mL}$ using hexane as a solvent, and then cleaned in an alumina-silica gel column (3\% water deactivated) topped with anhydrous sodium sulfate. The extracts were then eluted with $22 \mathrm{~mL}$ of hexane/dichloromethane (1:1) and reduced to a final volume of $0.5 \mathrm{~mL}$ with nitrogen (purity 99.999\%). As an internal standard, $20 \mathrm{ng}$ PCB-208 was added to the solvent.

Analysis was conducted by a gas chromatographer (GC) coupled with a 5975C mass selective detector (MSD) in the electron capture negative ion chemical ionization mode (ECNICI). A HP-5MS (30 m $\times$ $0.25 \mathrm{~mm}$ i.d., $0.25 \mathrm{~mm}$ film thickness) capillary column was used to determine the levels and composition of CUPs. The GC temperature program was set as follows: $60{ }^{\circ} \mathrm{C}$ for $1 \mathrm{~min}$, then increased to $150{ }^{\circ} \mathrm{C}$ at $30{ }^{\circ} \mathrm{C} \mathrm{min}-1$, and finally to $300{ }^{\circ} \mathrm{C}$ at $5{ }^{\circ} \mathrm{C} \mathrm{min}^{-1}$, which was held for $5 \mathrm{~min}$. The front inlet temperature was $290^{\circ} \mathrm{C}$, and the post-run temperature was $300{ }^{\circ} \mathrm{C}$. The ions 335 and 305 were monitored for trifluralin; ions $\mathrm{m} / \mathrm{z} 265.8$ and 229.9 for chlorothalonil; ions 312.8 and 168.9 for chlorpyrifos; and ions $m / z 249.9$ and 251.8 for dicofol.

\subsection{Quality assurance and quality control}

Glass vials, filters, silica gel, neutral alumina, and anhydrous sodium sulfate were baked at $450^{\circ} \mathrm{C}$ for $12 \mathrm{~h}$ prior to usage, and PUF/XAD-2 and 
XAD-2 columns were cleaned using a modified soxhlet extractor with methanol and hexane/acetone (1:1), respectively, for $24 \mathrm{~h}$. After cleaning, all columns were dried under gentle pure nitrogen (purity 99.999\%) for sampling, and the air columns were protected against UV-light using aluminum foil to avoid the target compounds degrading in the column during sampling. Field blanks for various samples at different stages were also collected during the campaigns. The mean recoveries of trifluralin-d14 were $123 \pm 8,134 \pm 19,176 \pm 29$, and 177 $\pm 14 \%$ for the air and water filters, and air and water columns, respectively. The high recovery could have been due to the evaporation of the keeper of the surrogate. The recovery was assessed by spike tests, the results of which were $75 \%$ for trifluralin, $78 \%$ for chlorothalonil, $89 \%$ forchlorpyrifos, and $95 \%$ for dicofol. The method detection limits (MDL) were calculated based on the mean blank values plus three times the standard deviations of the blanks. For this study, if the values were below the MDL, there were considered not detected (n.d.). Atmospheric MDLs ranged from 0.047 to $9.40 \mathrm{pg} \mathrm{m}^{-3}$, and seawater MDLs ranged from 0.24 to $78.26 \mathrm{pg} \mathrm{L}^{-1}$.

\subsection{Air mass back trajectories}

To identify the source region of CUPs in the air samples, air mass backward trajectories were calculated using NOAA's HYSPLIT model (Draxler and Rolph, 2003). Air mass backward trajectories (BTs) were modeled in $6 \mathrm{~h}$ intervals for $120 \mathrm{~h}$, with the sampling height as the arrival height, and the individual backward trajectories are shown in Fig. S2.

\section{Results and discussion}

\subsection{CUPs in air}

Concentrations of individual CUPs during different seasons are summarized in Table 1, and details are presented in Tables S5-S7. Generally, chlorpyrifos $\left(63.73 \pm 126.12 \mathrm{pg} \mathrm{m}^{-3}\right)$ was the most predominant compound, followed by chlorothalonil $\left(22.32 \pm 15.91 \mathrm{pg} \mathrm{m}^{-3}\right)$, dicofol $\left(17.66 \pm 22.12 \mathrm{pg} \mathrm{m}^{-3}\right)$, and trifluralin $\left(5 \pm 14.53 \mathrm{pg} \mathrm{m}^{-3}\right)$ (Figs. 1 and S3). In order to identify the characteristics of contaminants in particle phase more precisely, the concentration of CUPs in the particulate fraction (air and seawater) also expressed in weight (Tables S7 and $\mathrm{S} 10$ ). In our study, the particle-phase fractions $\left(\mathrm{f}_{\mathrm{p}}\right)$ of the three target compounds (excluding dicofol due to its low detection rate in particle phase) were noticeably higher in the winter (28-67\%) than summer (0-5\%) (Fig. 2). This trend is more apparent with the date expressed in weight. Four CUPs in air particle phase increased from summer $\left(82.23 \pm 58.02 \mathrm{ng} \mathrm{g}^{-1}\right)$ to winter $\left(444.29 \pm 513.79 \mathrm{ng} \mathrm{g}^{-1}\right)$. Previous studies have demonstrated that the partitions between gas and particle phases were probably controlled by physic-chemical properties of the compounds (e.g., vapor pressures $\left(\mathrm{P}_{\mathrm{L}}\right)$ ), or by meteorological conditions, such as temperature (Mader and Pankow, 2000, 2001a, 2001b; T. Xu et al., 2017).

Chlorpyrifos was one of the most abundant CUPs in gas phase of air samples above the Bohai Sea (135.05 $\pm 176.53 \mathrm{pg} \mathrm{m}^{-3}$ in August 2016; $7.91 \pm 11.61 \mathrm{pg} \mathrm{m}^{-3}$ in December $2016 ; 3.20 \pm 1.09 \mathrm{pg} \mathrm{m}^{-3}$ in February 2017) (Table 1). The concentration in August (135.05 \pm $176.53 \mathrm{pg} \mathrm{m}^{-3}$ ) was comparable with that reported in May 2012 in air (142.08 $\pm 176.30 \mathrm{pg} \mathrm{m}^{-3}$ ) (Zhong et al., 2014) (Table S3) in the Bohai Sea. Although the use of chlorpyrifos on vegetables ceased in China on December 31, 2014, this result suggested high consumption and application in the continents adjacent to the Bohai Sea, or continued use in China.

Chlorothalonil is a broad-spectrum organochlorine fungicide that is used to control fungi on vegetables, trees, and other agricultural crops (Estellano et al., 2015). Chlorothalonil was detected in all samples, with concentrations ranging from n.d. to $36.57 \mathrm{pg} \mathrm{m}^{-3}$ and 0.59 to $59.48 \mathrm{pg} \mathrm{m}^{-3}$ in the particle and gas phases, with averages of $6.53 \pm$ $7.97 \mathrm{pg} \mathrm{m}^{-3}$ and $15.79 \pm 17.25 \mathrm{pg} \mathrm{m}^{-3}$, respectively. The levels of chlorothalonil calculated in weight $\left(147.03 \pm 200.73 \mathrm{ng} \mathrm{g}^{-1}\right)$ have the highest concentration compared with other targets. The concentrations in the gaseous phase in August $\left(31.53 \pm 15.64 \mathrm{pg} \mathrm{m}^{-3}\right)$ were comparable to those from the Bohai Seas in May 2012 (31.02 \pm $31.31 \mathrm{pg} \mathrm{m}^{-3}$ ) (Zhong et al., 2014) (Table S3), but the mean values of all samples higher than those from the North Pacific and Arctic Oceans in $2010\left(0.64 \pm 1.8 \mathrm{pg} \mathrm{m}^{-3}\right.$ ) (Zhong et al., 2012a), and the western Arctic Ocean in 1993-2013 (0.90 $\left.\pm 1.8 \mathrm{pg} \mathrm{m}^{-3}\right)$ (Jantunen et al., 2015). This result suggested that chlorothalonil is widely used in China.

Dicofol was only identifiedin 4 of 22 samples in the particle phase (18\%), so the following discussion will focus on the gas phase. The mean concentration of dicofol was $16.07 \pm 22.85 \mathrm{pg} \mathrm{m}^{-3}$, similar to that of chlorothalonil, even though the annual use amount of dicofol in China was 10 times higher than that of chlorothalonil (Zhong et al., 2014). This could be due to the low Henry's law constant (HLC) and high $\log \mathrm{K}_{\mathrm{oa}}$ values of dicofol (Table S4). During the February 2017 sampling campaign, dicofol was only detected in one sample (FA1), which was taken near the Bohai Strait.

Trifluralin is a synthetic dinitroaniline herbicide, which is commonly used as a pre-emergence herbicide (Zhong et al., 2012b). Approximately 3719 and 2540 tons of trifluralin were used for agriculture in the US and China in 2010, respectively (Gong et al., 2016). Although trifluralin has not yet been listed as a persistent organic pollutant (POP), it was a candidate for becoming listed as a POP under the UNECE LRTP conventions (UNECE, 2009). Trifluralin was detected in most air samples (82\%). The concentrations of trifluralin were lower than those of other compounds (particle phase: $0.35 \pm 0.76 \mathrm{pg} \mathrm{m}^{-3}$, gas phase: $4.65 \pm 14.55 \mathrm{pg} \mathrm{m}^{-3}$ ) (Figs. 1 and S3), which may be due to the rapid degradation of trifluralin under sunlight and its short half-life of a few hours (Aulagnier et al., 2008 ) in the air and water. Trifluralin concentrations ranged from n.d.

Table 1

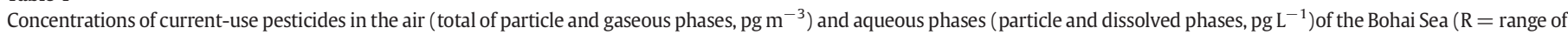
concentrations of the target compounds measured during the sampling periods; $M \pm S D=$ mean \pm standard deviation).

\begin{tabular}{|c|c|c|c|c|c|c|c|c|c|}
\hline & & \multicolumn{2}{|l|}{ Trifluralin } & \multicolumn{2}{|l|}{ Chlorothalonil } & \multicolumn{2}{|l|}{ Chlorpyrifos } & \multicolumn{2}{|l|}{ Dicofol } \\
\hline & & $\mathrm{R}$ & $\mathrm{M} \pm \mathrm{SD}$ & $\mathrm{R}$ & $\mathrm{M} \pm \mathrm{SD}$ & $\mathrm{R}$ & $\mathrm{M} \pm \mathrm{SD}$ & $\mathrm{R}$ & $\mathrm{M} \pm \mathrm{SD}$ \\
\hline \multirow{3}{*}{$\begin{array}{l}\text { Air particle phase } \\
\left(\mathrm{pg} \mathrm{m}^{-3}\right)\end{array}$} & Aug & $0.06-0.20$ & $0.11 \pm 0.05$ & $0.27-3.31$ & $1.58 \pm 1.27$ & $0.74-10.43$ & $2.54 \pm 3.06$ & & \\
\hline & Dec & n.d. -1.53 & $0.25 \pm 0.50$ & $2.33-13.56$ & $6.75 \pm 4.17$ & $1.18-8.59$ & $3.44 \pm 2.23$ & n.d.-7.85 & $0.87 \pm 2.62$ \\
\hline & Feb & $0.24-3.44$ & $1.09 \pm 1.57$ & $8.88-36.57$ & $17.17 \pm 13.03$ & $3.89-29.65$ & $12.24 \pm 11.82$ & n.d.-11.15 & $6.80 \pm 4.96$ \\
\hline \multirow{3}{*}{$\begin{array}{l}\text { Gas phase } \\
\left(\mathrm{pg} \mathrm{m}^{-3}\right)\end{array}$} & Aug & $0.16-69.03$ & $9.62 \pm 22.46$ & $13.30-59.47$ & $31.53 \pm 15.64$ & $15.38-550.04$ & $135.05 \pm 176.53$ & n.d. -87.39 & $29.45 \pm 29.71$ \\
\hline & Dec & n.d.-5.85 & $1.52 \pm 1.87$ & $0.59-19.42$ & $6.41 \pm 7.46$ & $0.74-34.55$ & $7.91 \pm 11.61$ & n.d. -24.98 & $8.97 \pm 11.14$ \\
\hline & Feb & $0.11-1.64$ & $0.53 \pm 0.74$ & $0.71-3.22$ & $1.47 \pm 1.19$ & $1.59-3.98$ & $3.20 \pm 1.09$ & n.d. -7.71 & $1.93 \pm 3.85$ \\
\hline \multirow{3}{*}{$\begin{array}{l}\text { Seawater particle phase } \\
\left(\operatorname{pg~L}^{-1}\right)\end{array}$} & Aug & n.d. -0.15 & $0.02 \pm 0.05$ & & & $1.02-454.14$ & $103.55 \pm 157.36$ & & \\
\hline & Dec & n.d. -1.98 & $0.40 \pm 0.66$ & & & n.d.-284.18 & $37.55 \pm 92.93$ & & \\
\hline & Feb & $0.63-1.50$ & $1.08 \pm 0.39$ & & & $1.34-7.06$ & $2.84 \pm 2.82$ & & \\
\hline \multirow{3}{*}{$\begin{array}{l}\text { Seawater dissolved phase } \\
\left(\mathrm{pg} \mathrm{L}^{-1}\right)\end{array}$} & Aug & n.d. -2.27 & $1.12 \pm 0.62$ & $11.53-37.25$ & $25.67 \pm 8.68$ & $106.87-219.42$ & $168.63 \pm 44.20$ & $339.08-365.48$ & $241.97 \pm 83.03$ \\
\hline & Dec & n.d. -2.20 & $0.44 \pm 0.72$ & n.d.-11.39 & $4.20 \pm 3.71$ & $23.13-55.95$ & $32.30 \pm 10.21$ & n.d.-68.99 & $7.67 \pm 22.99$ \\
\hline & Feb & $0.83-2.71$ & $1.32 \pm 0.92$ & $0.99-16.26$ & $4.96 \pm 7.53$ & $30.67-102.10$ & $53.53 \pm 32.72$ & $47.70-131.71$ & $75.99 \pm 37.82$ \\
\hline
\end{tabular}




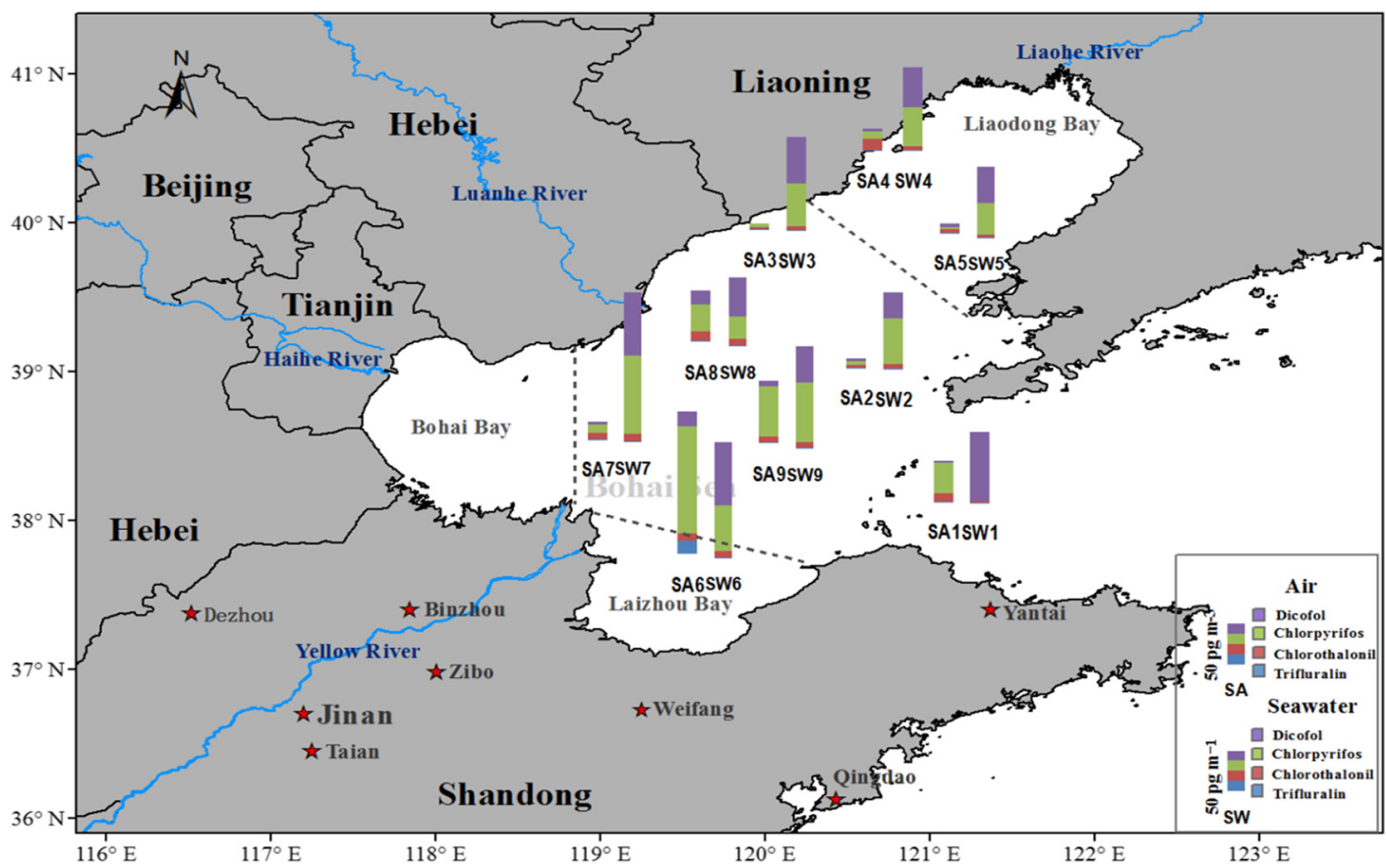

Fig. 1. Spatial distributions of the target compounds in the Bohai Sea in August 2016. (The sampling cruise began at SA1 (SW1) and traveled to SA9 (SW9)).

to $3.44 \mathrm{pg} \mathrm{m}^{-3}$ in the particulate phase and n.d. to $8.44 \mathrm{pg} \mathrm{m}^{-3}$ in the gas phase (excluding SA6, with concentration of $69.03 \mathrm{pg} \mathrm{m}^{-3}$ ). This peak coincided with the high values of the other three compounds in the same sample, and was likely associated with the same sources.

\subsection{Seasonal variations in the air}

CUPs concentrations showed clear seasonal patterns (Tables 1 and S12). Higher concentrations were identified in the gas phase in May 2012 and August 2016 than those in December 2016 and February 2017.In contrast, higher concentrations were observed in the particulate phase in the winter than in summer (see Table S7, Fig. S4).

In this study, the highest concentrations of pollutants in gas phase air samples were all detected in August, as follows: chlorpyrifos $\left(135.05 \pm 22.47 \mathrm{pg} \mathrm{m}^{-3}\right)$., chlorothalonil $\left(31.53 \pm 15.64 \mathrm{pg} \mathrm{m}^{-3}\right)$,

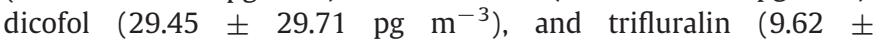
$22.47 \mathrm{pg} \mathrm{m}^{-3}$ ). Compared with previous study in spring (May 2012),

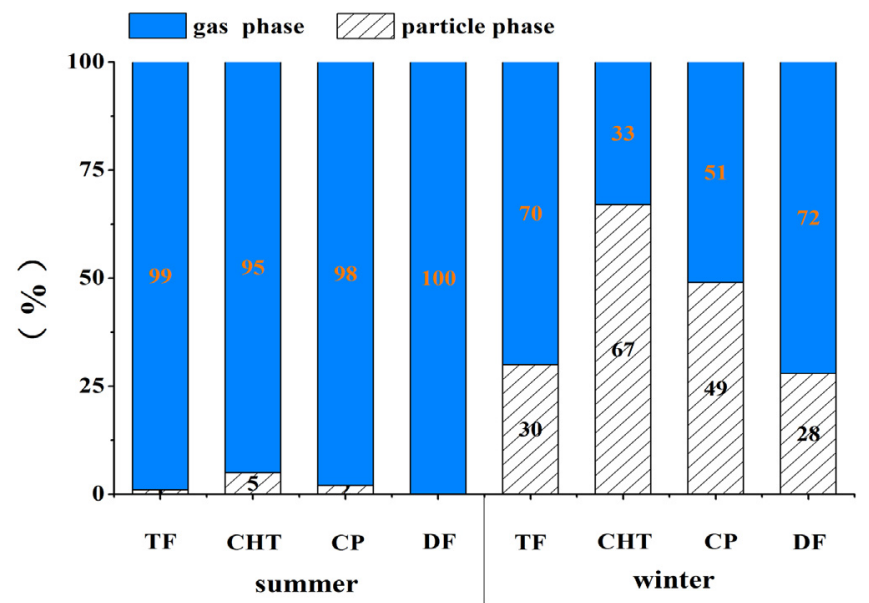

Fig. 2. Gas/particle partitioning of CUPs in the summer (August) and winter (December/ February); TF, trifluralin; CHT, chlorothalonil; CP, chlorpyrifos; DF, dicofol. the concentration of dicofol $\left(3.78 \pm 2.17 \mathrm{pg} \mathrm{m}^{-3}\right)$ increased significantly, which attributed to its immunity of many Chinese pesticide enterprises and a large amount of usage although it has been listed as a persistent toxic compound in a series of multilateral agreements. The concentration of other compounds was higher in spring and summer than that in winter. These observations could have been influenced by the agricultural fields that surround the Bohai Sea, which heavily used pesticides during the growing season for crop protection. The average air temperatures in August, December, and February were 23, 3, and 4 ${ }^{\circ} \mathrm{C}$, respectively. The increased ambient temperatures may accelerate the volatilization of pesticides from the surface to the atmosphere in August. Similar seasonality in the atmosphere has also been observed previously, with higher levels of CUPs during the spring or summer periods (Estellano et al., 2015; Hart et al., 2012; Mai et al., 2013). On the contrary, the concentration of target compounds in particle phase in winter $\left(444.29 \pm 513.79 \mathrm{ng} \mathrm{g}^{-1}\right)$ was higher than that in summer $(82.23 \pm$ $58.02 \mathrm{ng} \mathrm{g}^{-1}$ ) (Table S7). One of the influencing factors may be lower temperature in winter, which could lead to high proportions of semivolatile organic compounds (SVOCs) in the fine particles (Jin et al., 2017). Total suspended particulate (TSP) concentration was also calculated in the sampling air (Table S11). The trend corresponded to their seasonality of $f_{p}$, which has the significantly increased concentration from summer $\left(57 \mu \mathrm{g} \mathrm{m}^{-3}\right)$ to winter $\left(68 \mu \mathrm{g} \mathrm{m}^{-3}\right)$. This result reflected the concentration of CUPs could increase with increasing concentration of particles. Dicofol was scarcely found in particle phase during the sampling campaign. In contrast, dicofol displayed a widespread distribution in gas phase in samples collected from the Bohai Sea in August 2016 (89\%), and was also detected in 44\% of the samples in December 2016. The presence of pollutants in the particulate phase depends on the physicochemical properties of each compound (Carratala et al., 2017); the lower detection rate might be attributed to the higher $\log \mathrm{K}_{\text {oa }}$ value of dicofol (Table S4).

To gain a general understanding of the sources of the target compounds in different seasons, backward trajectories (BTs) of air masses were calculated to trace the most likely paths of the air parcel that collected them. In August, air masses in the Bohai Sea were influenced by southerly, south-westerly, and south-easterly winds that passed through East China (Tianjin Municipality, and the Hebei, Shandong, 
Jiangsu, and Anhui Provinces) and its adjacent waters, occasionally passing through Liaoning Province and Inner Mongolia. The samples with elevated concentrations were associated with air masses passing through the eastern coastal area of China (see Fig. 4SA6), where agriculturalization and industrialization activities have rapidly developed, discharging large amounts of pesticides to the Bohai Sea (Hu et al., 2009; Pan et al., 2016; Wang et al., 2008). This indicates high levels of pollution from terrestrial sources. It is evident that the samples with relatively low concentrations in August could be associated with cleaner air masses originating from the open sea areas near eastern China (Fig. 4SA3). In December 2016 and February 2017, air masses over the Bohai Sea were influenced by northerly and north-westerly winds that primarily traveled through the Hebei and Liaoning Provinces, the Inner Mongolia Autonomous Region, Mongolia, and Russia. The concentrations in the air of these regions were lower than those in the air masses above the Bohai Rim.

\subsection{CUPs in seawater}

The concentrations of the four compounds in the dissolved and particle phases are provided in Tables S8-S10. Among the four CUPs, chlorpyrifos was present in both phases, and trifluralin was only detectable in a few filtered seawater samples. The concentrations of all four compounds expressed in volume were primarily higher in the dissolved phase than in the particulate phase. Chlorpyrifos, with the mean value $181.56 \pm 163.04 \mathrm{pg} \mathrm{g}^{-1}$, was the predominant contaminant found in particle fraction expressed in weight, followed by trifluralin $(25.09 \pm$ $28.12 \mathrm{pg} \mathrm{g}^{-1}$ ), while chlorothalonil and dicofol were almost not detected. The concentrations of the target compounds in the dissolved phase ranged from n.d. to $365.48 \mathrm{pg} \mathrm{L}^{-1}$ (trifluralin: $0.88 \pm 0.78 \mathrm{pg} \mathrm{L}^{-1}$, chlorothalonil: $13.12 \pm 12.50 \mathrm{pg} \mathrm{L}{ }^{-1}$, chlorpyrifos: $88.28 \pm$ $71.55 \mathrm{pg} \mathrm{L}^{-1}$, and dicofol: $115.94 \pm 123.16 \mathrm{pg} \mathrm{L}^{-1}$ ), excluding chlorpyrifos in SW1 (2150.87 $\mathrm{pg} \mathrm{L}^{-1}$ ), which was one or two orders of magnitude higher than the concentrations in the other samples. The following discussion about chlorpyrifos will not include this outlier.

The concentrations of dicofol in the dissolved phase were higher than those of the other three pesticides. This was consistent with the properties of dicofol, with water solubility $\left(S_{L}\right)$ at least an order of 100 times higher and Henry's law constants (HLCs) 100 times lower than those of the other compounds (Table S4). The mean dicofol concentration measured in this study was slightly higher than those observed in the Bohai Sea in $2012\left(89.57 \pm 72.05\right.$ pg L $\left.^{-1}\right)$ (Zhong et al., 2014) (Table S3), and was markedly higher than those reported in the North Pacific and the Arctic Oceans $\left(9 \pm 23\right.$ pg L $\left.^{-1}\right)$ (Zhong et al., 2012a) (Table S3), and the India-Pacific sector of the Southern Ocean ( $<$ MDLs) (Marie et al., 2016) (Table S3). Although the pesticide registration of dicofol was banned in China, high levels in the Bohai Sea could have been due to the large use of dicofol, with domestic consumption of 19,500 tons from 2000 to 2012 , occupying $69 \%$ of the global total (Li et al., 2015).

Higher concentrations of the four compounds were present in SW6 and SW7 in August, which were sampled close to the interface between the Bohai Bay (BB) and Laizhou Bay (LB) (Fig. 1). The spatial distribution found for CUPs in the Bohai Sea was similar to that found in May 2012, which high concentration areas were also present in the BB and LB. BB and LB are in the northern part of Shandong Province, which uses the highest amount of pesticides in China (www.stats.gov.cn). Two of the top ten enterprises that led China's pesticide sales in 2016 were located in Weifang and Binzhou, which are close to the LB and BB, respectively. In addition to these two cities, Tianjin Municipality, and Qingdao, Jinan, Dezhou, Taian, and Yantai have also contributed to the large amounts of CUPs (www.agrichem.cn). From Fig. 1, it can be seen that these places around BB and LB are the most prominent terrestrial sources of CUPs. Studies have shown that pollutants could enter the BB and LB through riverine inputs during the application period (L. Xu et al., 2017; Zhao et al., 2017; Zheng et al., 2011; Zhong et al., 2011). The target compounds are expected to discharge into the Bohai Sea through the runoff of the Yellow and Haihe Rivers (Fig. 1), which are among the seven largest water systems in China, and receive large volumes of industrial or agricultural wastewater leading to serious pollution levels (Li et al., 2013; Li et al., 2016). For example, the Yellow River flows through Zibo City, which is the largest production base of Chlorpyrifos in Northern China $(15,000 \mathrm{t} / \mathrm{y})$, this may explain the high concentration of Chlorpyrifos in SW6 and SW7. The target concentrations in this area are notably lower in winter, which may be ascribed to the decrease of pesticide use (Fig. S3).

The CUPs in particle phase were mostly below the MDLs in seawater, excluding chlorpyrifos ( $181.56 \pm 163.04 \mathrm{pg} \mathrm{g}^{-1}$ ) (Table S10). Thus, the seasonal trends of particle phase will not be discussed further.

\subsection{Seasonal variations in seawater}

The seasonal patterns of pesticides in seawater are shown in Fig. 3B.The highest concentrations of the three CUPs (excluding trifluralin) in the dissolved phase were identified in August, and the mean concentrations were as follows: chlorothalonil $\left(25.67 \pm 8.68 \mathrm{pg} \mathrm{L}^{-1}\right)$, chlorpyrifos (168.63 $\left.\pm 44.2 \mathrm{pg} \mathrm{L}^{-1}\right)$, and dicofol (241.97 \pm $\left.83.03 \mathrm{pg} \mathrm{L}^{-1}\right)$.The mean concentrations of trifluralin in February slightly exceeded the values measured in August due to usage as pre-emergence herbicides to protect winter grains (Mai et al., 2013). Low temperatures and low solar radiation intensity in winter may severely decrease the hydrolysis and photolysis of these compounds, and therefore increase their environmental half-lives (Chernyak et al., 1996). Compared with this study, the concentration of contaminants (excluding trifluralin) in May 2012 only next to that in August 2016 (Table S13). The most predominant contaminant in the summer was dicofol (August 2016: $241.97 \pm 83.03 \mathrm{pg} \mathrm{L}^{-1}$ ), while chlorpyrifos was the most predominant in the spring and winter (May: $98.29 \pm 132.1 \mathrm{pg} \mathrm{L}^{-1}$, December 2016, February 2017: $38.83 \pm 21 \mathrm{pg} \mathrm{L}^{-1}$ ). Dicofol is not susceptible to high temperatures and solar radiation intensity owing to its high water solubility $\left(\mathrm{S}_{\mathrm{L}}\right)$ (Table $\mathrm{S} 4$ ) compared to the other target compounds. Thus, the concentrations of dicofol were high in seawater in summer.

\subsection{Air-sea gas exchange}

To estimate the direction of gas exchange (state of phase equilibri$\mathrm{um}$ ) between the two phases, the fugacity ratio $\left(\mathrm{FR}, f_{a} / f_{w}\right)$ was calculated for each paired air-seawater sample for the CUPs with sufficient detection frequency (trifluralin, chlorothalonil, and chlorpyrifos) using the Whitman two-film model (Liss and Slater, 1974; Terry and Bidleman, 1995) (Table S15). The FR was calculated by:

$\mathrm{FR}=f_{a} / f_{w}=\mathrm{c}_{\mathrm{a}} \mathrm{RT}_{\mathrm{a}} /\left(\mathrm{c}_{\mathrm{w}} \mathrm{H}_{\mathrm{T}, \text { sal. }}\right)$

where $\mathrm{c}_{\mathrm{a}}$ is the gas phase concentration $\left(\mathrm{ng} \mathrm{m}^{-3}\right), \mathrm{c}_{\mathrm{w}}$ is the dissolved phase concentration (ng $\mathrm{L}^{-1}$ ), $\mathrm{R}$ is the universal gas constant (8.31 $\mathrm{Pa} \mathrm{m}^{3} \mathrm{k}^{-1} \mathrm{~mol}^{-1}$ ), and $\mathrm{T}_{\mathrm{a}}$ is the air temperature $(\mathrm{K})$, which was measured by the research vessel. Henry's law constant $\mathrm{H}_{\mathrm{T}}$, sal $(\mathrm{Pa}$ $\mathrm{m}^{3} \mathrm{~mol}^{-1}$ ) was corrected by water temperature and salinity (Table S14). By considering the uncertainty of the water and air concentrations, Henry's law constants, and air temperature during sampling, an equilibrium window for the CUPs was set up as follows: $0.3<$ FR < 3.0 (Bruhn et al., 2003; Lammel et al., 2015; Zhong et al., 2012a). FR $>3.0$ indicates net deposition, and FR $<0.3$ indicates net volatilization. Comparison of FR values in air and seawater (Fig. 5) indicated that net volatilization is driven by the relatively high concentrations in seawater and low concentrations in the atmosphere. For instance, the FRs for trifluralin and chlorpyrifos in most samples were $<0.3$ due to their lower concentrations in air than seawater.

The FRs of chlorothalonil showed a stronger net deposition than other compounds, especially in December (mean FR: 94.92) (see Fig. 5), and the maximum value was identified in WA3 (WW3). The 

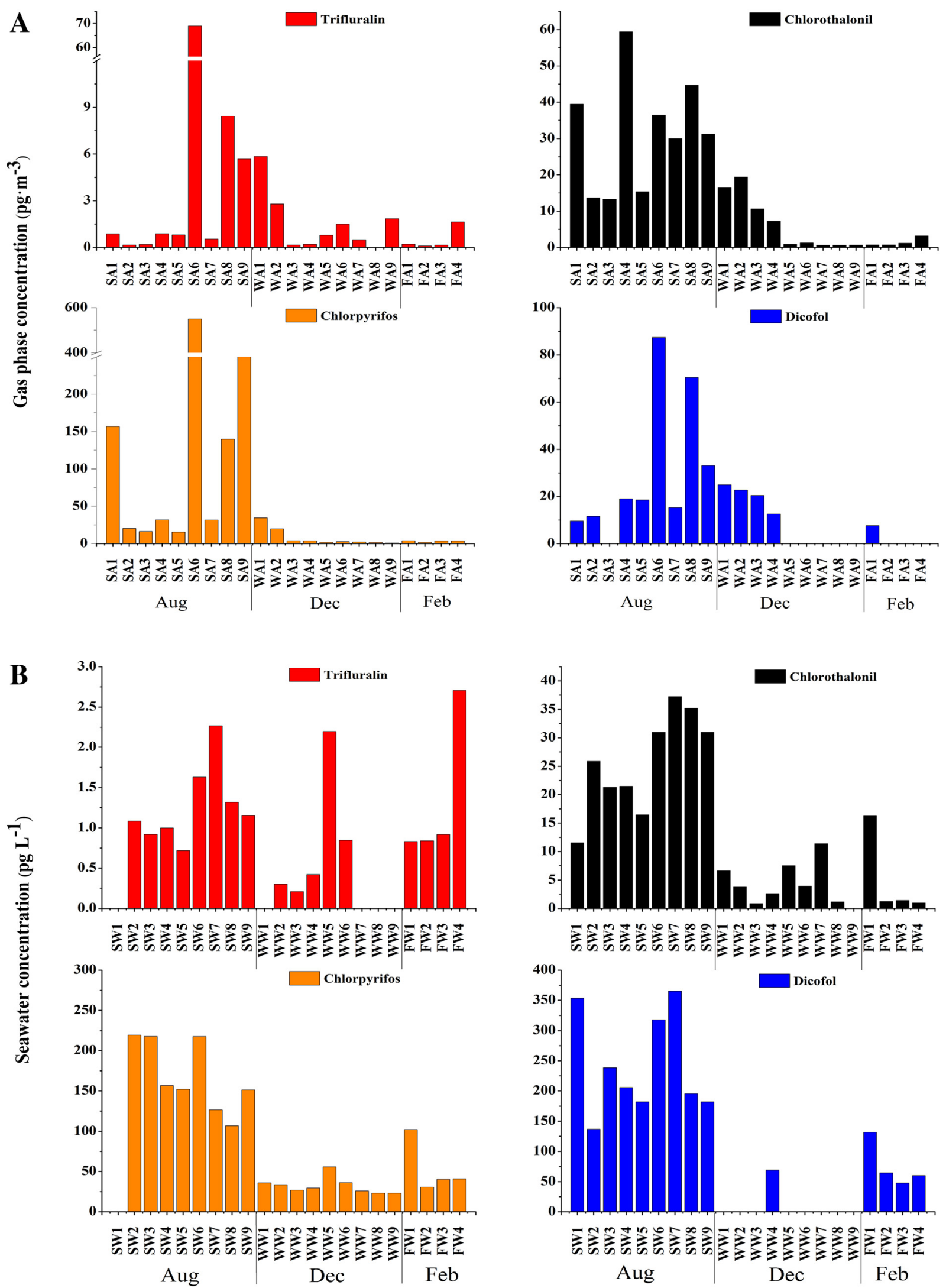

Fig. 3. Concentrations of CUPs in the gas phase (A, unit: $\mathrm{pg} \mathrm{m}^{-3}$ ) and dissolved phase in seawater (B, unit: pg L ${ }^{-1}$ ) in August/December 2016 and February 2017.

low concentrations of chlorothalonil in surface seawater samples supported continued deposition from air to water. The calculated FRs indicated that the Bohai Sea continued to act as a sink for chlorothalonil.
Trifluralin showed net volatilization over most of the sampling period. This result was consistent with previous work conducted in the Bohai Sea (Zhong et al., 2014). The direction of air-water gas exchange could 

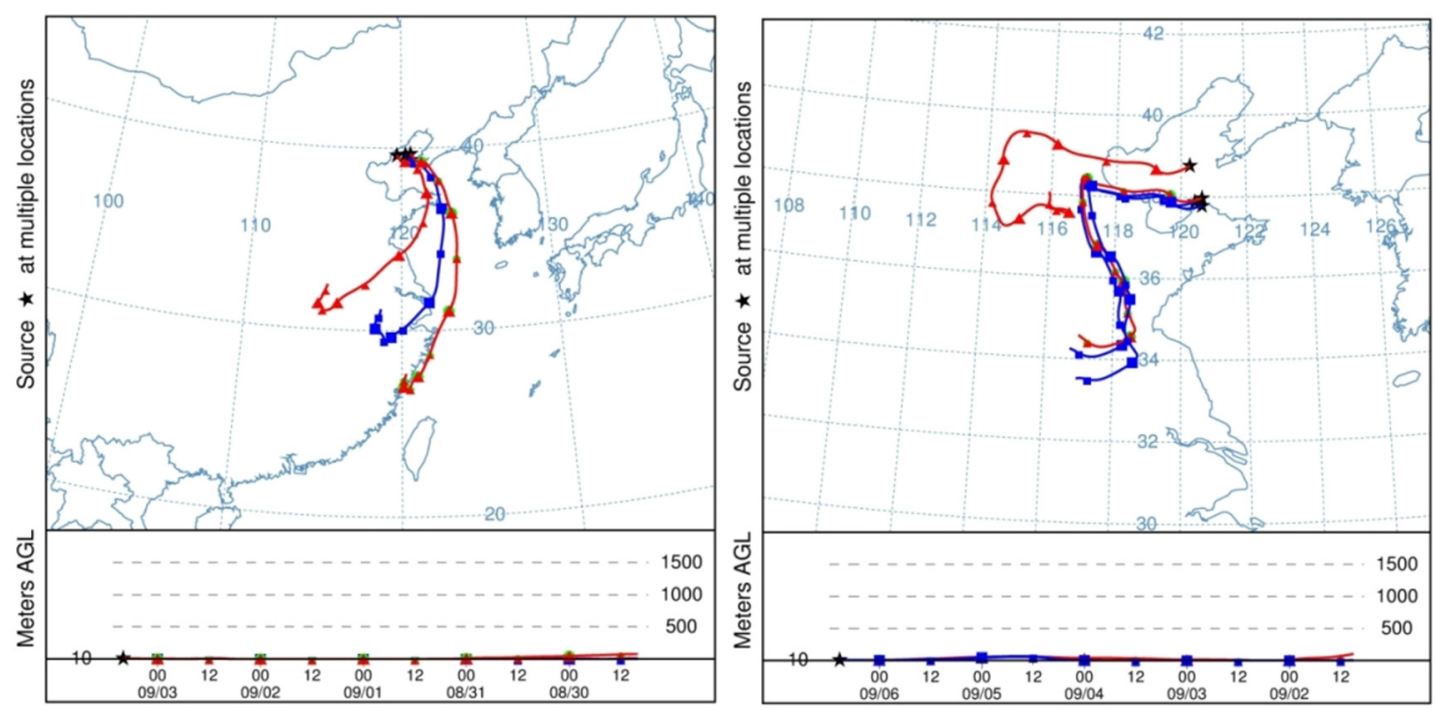

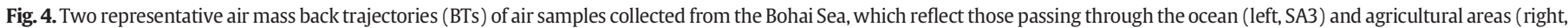
SA6).

be attributed to trifluralin's low water solubility and high volatility. Chlorpyrifos also showed net volatilization in most of the sampling areas, but the mean FR values of the three sampling periods were near the equilibrium (August: 0.38, December: 0.48, February: 0.24). The half-life of chlorpyrifos in air is an order of 100 times lower than that in seawater, $<1$ day, which could cause relatively higher concentrations in seawater, and have limited potential for LRAT (Muir et al., 2004; Zhong et al., 2014). River discharges is likely to have higher influence for seawater CUPs concentration than air deposition according to our study. In recent years, the distribution of pesticides in rivers around the Bohai Sea in China has been reported by several research groups (Feng et al., 2011; Hu et al., 2010; Tan et al., 2009; Zhong et al., 2011). The highly developed system of agriculture along the river use a large number of pesticides, which applied in the BER may enter Bohai Sea through surface runoff, creating the higher concentration of many contaminants than that in upper atmosphere. Our study confirms that airseawater exchange is an important pathway for the transport and fate of pollutants. Similarly, the oceans are gradually becoming second sources of POPs to the atmosphere.

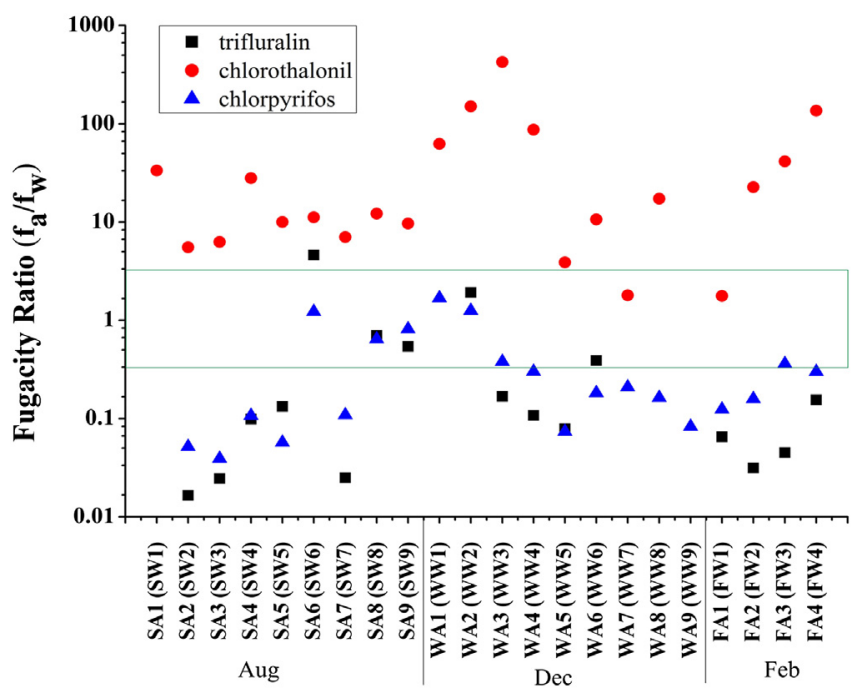

Fig. 5. The air-seawater exchange fugacity ratios ( $\mathrm{fa} / \mathrm{fw}$ ) of trifluralin, chlorothalonil and chlorpyrifos in the Bohai Sea. The green border highlights an equilibrium window of 0.3 $<\mathrm{f}_{\mathrm{a}} / \mathrm{f}_{\mathrm{w}}<3$. (For interpretation of the references to colour in this figure legend, the reader is referred to the web version of this article.)

\section{Conclusion}

This study showed the spatial and seasonal distribution of CUPs in the Bohai Sea, and air mass back trajectories and air-sea exchange were examined to determine the various input sources of CUPs into this area. Trifluralin, chlorothalonil, chlorpyrifos, and dicofol were frequently observed and showed strong seasonal fluctuations in air. Their abundances in air and water were determined by heavy usage during the growing seasons. Back trajectories indicated that samples with elevated concentrations were associated with air masses passing through the eastern coastal area of China (Tianjin Municipality, and the Hebei, Shandong, Jiangsu, and Anhui Provinces), where agricultural production, urbanization, and industrial activities are rapidly growing, leading to the discharge of large amounts of pesticides to the Bohai Sea. The seasonality of target compounds in seawater was not as apparent as that in the air. Higher concentrations of dicofol measured in dissolved phase in the Bohai Sea could be due to the widespread usage of dicofol in China, and the lower HLCs and higher $\log \mathrm{K}_{\text {oa }}$ values of dicofol also lead to its high abundance in seawater. Volatilization from surface water was proven to be an important source of trifluralin and chlorpyrifos in the air. Atmospheric deposition was found to be a significant input pathway of chlorothalonil into the surface of the Bohai Sea, which has become the second highest source of trifluralin and chlorpyrifos to the atmosphere. As the influence of riverine inputs should be based on samples from rivers and estuaries around the Bohai Sea, further research is still required to identify the multiple factors affecting pesticides.

\section{Acknowledgments}

This study was supported by the National Science Foundation of China (41773138) and the Chinese Academy of Sciences (XDA11020401, 2013T2Z0032, and 13337KYSB20130013).

\section{Appendix A. Supplementary data}

Supplementary data to this article can be found online at https://doi. org/10.1016/j.scitotenv.2017.11.282.

\section{References}

Arinaitwe, K., Kiremire, B.T., Muir, D.C., Fellin, P., Li, H., Teixeira, C., Mubiru, D.N., 2016 Legacy and currently used pesticides in the atmospheric environment of Lake Victoria, East Africa. Sci. Total Environ. 543, 9-18. 
Asman, W.A.H., Jorgensen, A., Bossi, R., Vejrup, K.V., Mogensen, B.M., Glasius, M., 2005. Wet deposition of pesticides and nitrophenols at two sites in Denmark: measurements and contributions from regional sources. Chemosphere 59, 1023-1031.

Aulagnier, F., Poissant, L., Brunet, D., Beauvais, C., Pilote, M., Deblois, C., Dassylva, N., 2008. Pesticides measured in air and precipitation in the Yamaska Basin (Québec): occurrence and concentrations in 2004. Sci. Total Environ. 394, 338-348.

Bigot, M., Muir, D.C., Hawker, D.W., Cropp, R., Dachs, J., Teixeira, C.F., Bengtson Nash, S., 2016. Air-seawater exchange of organochlorine pesticides in the Southern Ocean between Australia and Antarctica. Environ. Sci. Technol. 50, 8001-8009.

Bruhn, R., Lakaschus, S., McLachlan, M.S., 2003. Air/sea gas exchange of PCBs in the southern Baltic Sea. Atmos. Environ. 37, 3445-3454.

Carratala, A., Moreno-Gonzalez, R., Leon, V.M., 2017. Occurrence and seasonal distribution of polycyclic aromatic hydrocarbons and legacy and current-use pesticides in air from a Mediterranean coastal lagoon (Mar Menor, SE Spain). Chemosphere 167, 382-395.

Chernyak, S.M., Rice, C.P., Mcconnell, L.L., 1996. Evidence of currently-used pesticides in air, ice, fog, seawater and surface microlayer in the Bering and Chukchi seas. Mar. Pollut. Bull. 32, 410-419.

Coscollà, C., Muñoz, A., Borrás, E., Vera, T., Ródenas, M., Yusà, V., 2014. Particle size distributions of currently used pesticides in ambient air of an agricultural Mediterranean area. Atmos. Environ. 95, 29-35.

Coscolla, C., Lopez, A., Yahyaoui, A., Colin, P., Robin, C., Poinsignon, Q., Yusa, V., 2017. Human exposure and risk assessment to airborne pesticides in a rural French community. Sci. Total Environ. 584-585, 856-868.

Draxler, R.R., Rolph, G.D., 2003. HYSPLIT (Hybrid Single Particle Lagrangian Integrated Trajectory) Model.

Estellano, V.H., Pozo, K., Efstathiou, C., Pozo, K., Corsolini, S., Focardi, S., 2015. Assessing levels and seasonal variations of current-use pesticides (CUPs) in the Tuscan atmosphere, Italy, using polyurethane foam disks (PUF) passive air samplers. Environ. Pollut. 205, 52-59.

Feng, J., Zhai, M., Liu, Q., Sun, J., Guo, J., 2011. Residues of organochlorine pesticides (OCPs) in upper reach of the Huaihe River, East China. Ecotoxicol. Environ. Saf. 74, $2252-2259$

Feng, J., Hu, P., Zhang, F., Sun, J., 2016. HCHs and DDTs in Yellow River of Henan section-a typical agricultural area in China: levels, distributions and risks. Environ. Geochem. Health 38, 1241-1253.

Gong, W., Liu, X., Xia, S., Liang, B., Zhang, W., 2016. Abiotic reduction of trifluralin and pendimethalin by sulfides in black-carbon-amended coastal sediments. J. Hazard. Mater. 310, 125-134.

Hageman, K.J., Simonich, S.L., Campbell, D.H., Wilson, G.R., Landers, D.H., 2006. Atmospheric deposition of current-use and historic-use pesticides in snow at nationa parks in the Western United States. Environ. Sci. Technol. 40, 3174-3180.

Hart, E., Coscollà, C., Pastor, A., Yusà, V., 2012. GC-MS characterization of contemporary pesticides in PM10 of Valencia Region, Spain. Atmos. Environ. 62, 118-129.

Hoferkamp, L., Hermanson, M.H., Muir, D.C., 2010. Current use pesticides in Arctic media; 2000-2007. Sci. Total Environ. 408, 2985-2994.

Hu, L., Zhang, G., Zheng, B., Qin, Y., Lin, T., Guo, Z., 2009. Occurrence and distribution of organochlorine pesticides (OCPs) in surface sediments of the Bohai Sea, China. Chemosphere 77, 663-672.

Hu, W., Wang, T., Khim, J.S., Luo, W., Jiao, W., Lu, Y., Naile, J.E., Chen, C., Zhang, X., Giesy, J.P., 2010. $\mathrm{HCH}$ and DDT in sediments from marine and adjacent riverine areas of North Bohai Sea, China. Arch. Environ. Contam. Toxicol. 59, 71-79.

Jantunen, L.M., Wong, F., Gawor, A., Kylin, H., Helm, P.A., Stern, G.A., Strachan, W.M., Burniston, D.A., Bidleman, T.F., 2015. 20 years of air-water gas exchange observation for pesticides in the western Arctic Ocean. Environ. Sci. Technol.49, 13844-13852.

Jin, R., Zheng, M., Yang, H., Yang, L., Wu, X., Xu, Y., Liu, G., 2017. Gas-particle phase partitioning and particle size distribution of chlorinated and brominated polycyclic aromatic hydrocarbons in haze. Environ. Pollut. 231, 1601-1608.

Lammel, G., Audy, O., Besis, A., Efstathiou, C., Eleftheriadis, K., Kohoutek, J., Kukucka, P., Mulder, M.D., Pribylova, P., Prokes, R., Rusina, T.P., Samara, C., Sofuoglu, A., Sofuoglu, S.C., Tasdemir, Y., Vassilatou, V., Voutsa, D., Vrana, B., 2015. Air and seawater pollution and air-sea gas exchange of persistent toxic substances in the Aegean Sea: spatial trends of PAHs, PCBs, OCPs and PBDEs. Environ. Sci. Pollut. Res. Int. 22, 11301-11313.

Li, C., Zheng, M., Gao, L., Zhang, B., Liu, L., Xiao, K., 2013. Levels and distribution of PCDD/Fs, dl-PCBs, and organochlorine pesticides in sediments from the lower reaches of the Haihe River basin, China. Environ. Monit. Assess. 185, 1175-1187.

Li, L., Liu, J., Hu, J., 2015. Global inventory, long-range transport and environmental distribution of dicofol. Environ. Sci. Technol. 49, 212-222.

Li, J., Chen, C., Li, F., 2016. Status of POPs accumulation in the Yellow River Delta: from distribution to risk assessment. Mar. Pollut. Bull. 107, 370-378.

Liss, P.S., Slater, P.G., 1974. Flux of gases across air-sea interface. Nature 247, 181-184

Liu, Y., Song, C., Li, Y., Liu, Y., Song, J., 2012. The distribution of organochlorine pesticides (OCPs) in surface sediments of Bohai Sea Bay, China. Environ. Monit. Assess. 184, 1921-1927.

Luek, J.L., Dickhut, R.M., Cochran, M.A., Falconer, R.L., Kylin, H., 2017. Persistent organic pollutants in the Atlantic and southern oceans and oceanic atmosphere. Sci. Total Environ. 583, 64-71.

Mader, B.T., Pankow, J.F., 2000. Gas/solid partitioning of semivolatile organic compounds (SOCS) to air filters. 1. Partitioning of polychlorinated dibenzodioxins, polychlorinated dibenzofurans and polycyclic aromatic hydrocarbons to teflon membrane filters. Atmos. Environ. 34, 4879-4887.

Mader, B.T., Pankow, J.F., 2001a. Gas/solid partitioning of semivolatile organic compound (SOCs) to air filters. 2. Partitioning of polychlorinated dibenzodioxins, polychlorinated dibenzofurans, and polycyclic aromatic hydrocarbons to quartz fiber filters. Atmos. Environ. 35, 1217-1223.

Mader, B.T., Pankow, J.F., 2001b. Gas/solid partitioning of semivolatile organic compounds (SOCs) to air filters. 3. An analysis of gas adsorption artifacts in measurements of atmospheric SOCs and organic carbon (OC) when using Teflon membrane filters and quartz fiber filters. Environ. Sci. Technol. 35, 3422-3432.

Mai, C., Theobald, N., Lammel, G., Hühnerfuss, H., 2013. Spatial, seasonal and vertical distributions of currently-used pesticides in the marine boundary layer of the North Sea. Atmos. Environ. 75, 92-102.

Mai, C., Theobald, N., Huhnerfuss, H., Lammel, G., 2016. Persistent organochlorine pesticides and polychlorinated biphenyls in air of the North Sea region and air-sea exchange. Environ. Sci. Pollut. Res. Int. 23, 23648-23661.

Marie, B., C, G., M, D., W, H.D., Roger, C., Jordi, D., F, T.C., Bengtson, N.S., 2016. Air-seawater exchange of organochlorine pesticides in the Southern Ocean between Australia and Antarctica. Environ. Sci. Technol. 8001.

Morris, A.D., Muir, D.C., Solomon, K.R., Letcher, R.J., McKinney, M.A., Fisk, A.T., McMeans, B.C., Tomy, G.T., Teixeira, C., Wang, X., Duric, M., 2016. Current-use pesticides in seawater and their bioaccumulation in polar bear-ringed seal food chains of the Canadian Arctic. Environ. Toxicol. Chem. 35, 1695-1707.

Muir, D.C.G., Teixeira, C., Wania, F., 2004. Empirical and modeling evidence of regional atmospheric transport of current-use pesticides. Environ. Toxicol. Chem. 23, 2421-2432.

Pan, H., Geng, J., Qin, Y., Tou, F., Zhou, J., Liu, M., Yang, Y., 2016. PCBs and OCPs in fish along coastal fisheries in China: distribution and health risk assessment. Mar. Pollut. Bull. $111,483-487$.

Scheyer, A., Morville, S., Mirabel, P., Millet, M., 2007. Variability of atmospheric pesticide concentrations between urban and rural areas during intensive pesticide application. Atmos. Environ. 41, 3604-3618.

Tan, L., He, M., Men, B., Lin, C., 2009. Distribution and sources of organochlorine pesticides in water and sediments from Daliao River estuary of Liaodong Bay, Bohai Sea (China). Estuar. Coast. Shelf Sci. 84, 119-127.

Terry, F., Bidleman, L.L.M., 1995. A review of field experiments to determine air-water gas exchange of persistent organic pollutants. Sci. Total Environ. 159, 101-117.

UNECE, 2009. Sumary of Peer Review Technical Review Comments on Trifluralin Submitted Under the UNECE-LRTAP POP's Protocol.

Walker, B., Nidiry, J., 2002. Current concepts: organophosphate toxicity. Inhal. Toxicol. 14, 975-990.

Wang, Y., Wang, T., Li, A., Fu, J., Wang, P., Zhang, Q., Jiang, G., 2008. Selection of bioindicators of polybrominated diphenyl ethers, polychlorinated biphenyls, and organochlorine pesticides in mollusks in the Chinese Bohai Sea. Environ. Sci. Technol. 7159-7165.

Xie, Z., Moller, A., Ahrens, L., Sturm, R., Ebinghaus, R., 2011. Brominated flame retardants in seawater and atmosphere of the Atlantic and the Southern Ocean. Environ. Sci. Technol. 45, 1820-1826.

Xu, L., Wang, T., Wang, J., Lu, A., 2017. Occurrence, speciation and transportation of heavy metals in 9 coastal rivers from watershed of Laizhou Bay, China. Chemosphere 173, 61-68.

Xu, T., Jiang, L., Yang, X., Chen, J., Cheng, T., Li, X., 2017. Design and application of a novel integrated microsampling system for simultaneous collection of gas- and particlephase semivolatile organic compounds. Atmos. Environ. 149, 1-11.

Yao, Y., Tuduri, L., Harner, T., Blanchard, P., Waite, D., Poissant, L., Murphy, C., Belzer, W., Aulagnier, F., Li, Y.-F., Sverko, E., 2006. Spatial and temporal distribution of pesticide air concentrations in Canadian agricultural regions. Atmos. Environ. 40, 4339-4351.

Yao, Y., Harner, T., Blanchard, P., Tuduri, L., Waite, D., Poissant, L., Murphy, C., Belzer, W., Aulagnier, F., Sverko, E., 2008a. Pesticides in the atmosphere across Canadian agricultural regions. Environ. Sci. Technol. 42, 5931-5937.

Yao, Y., Harner, Tom, Blanchard, Pierrette, Ludovic Tuduri, D.W., Laurier Poissant, C.M., Wayne Belzer, F.A., Sverko, A.E., 2008b. Pesticides in the atmosphere across Canadian agricultural regions. Environ. Sci. Technol. 5931-5937.

Zhao, Z., Tang, J., Mi, L., Tian, C., Zhong, G., Zhang, G., Wang, S., Li, Q., Ebinghaus, R., Xie, Z. Sun, H., 2017. Perfluoroalkyl and polyfluoroalkyl substances in the lower atmosphere and surface waters of the Chinese Bohai Sea, Yellow Sea, and Yangtze River estuary. Sci. Total Environ. 599-600, 114-123.

Zheng, B., Zhao, X., Liu, L., Li, Z., Lei, K., Zhang, L., Qin, Y., Gan, Z., Gao, S., Jiao, L., 2011. Effects of hydrodynamics on the distribution of trace persistent organic pollutants and macrobenthic communities in Bohai Bay. Chemosphere 84, 336-341.

Zhong, G., Tang, J., Zhao, Z., Pan, X., Chen, Y., Li, J., Zhang, G., 2011. Organochlorine pesticides in sediments of Laizhou Bay and its adjacent rivers, North China. Mar. Pollut. Bull. 62, 2543-2547.

Zhong, G., Xie, Z., Cai, M., Moller, A., Sturm, R., Tang, J., Zhang, G., He, J., Ebinghaus, R., 2012a. Distribution and air-sea exchange of current-use pesticides (CUPs) from East Asia to the high Arctic Ocean. Environ. Sci. Technol. 46, 259-267.

Zhong, G., Xie, Z., Möller, A., Halsall, C., Caba, A., Sturm, R., Tang, J., Zhang, G., Ebinghaus, R., 2012b. Currently used pesticides, hexachlorobenzene and hexachlorocyclohexanes in the air and seawater of the German Bight (North Sea). Environ. Chem. 9, 405-414.

Zhong, G., Tang, J., Xie, Z., Möller, A., Zhao, Z., Sturm, R., Chen, Y., Tian, C., Pan, X., Qin, W., Zhang, G., Ebinghaus, R., 2014. Selected current-use and historic-use pesticides in air and seawater of the Bohai and Yellow Seas, China. Atmospheres 119, 1073-1086. 